\title{
THERMAL RESPONSE TO FIRE OF UNIFORMLY INSULATED STEEL MEMBERS: BACKGROUND AND VERIFICATION OF THE FORMULATION RECOMMENDED BY CHINESE CODE CECS200
}

\author{
Guo-qiang $\mathrm{Li}^{1,2}$ and Chao Zhang ${ }^{2, *}$ \\ ${ }^{1}$ Sate Key Laboratory for Disaster Reduction in Civil Engineering, 1239 Siping Road, Shanghai, China \\ ${ }^{2}$ College of Civil Engineering, Tongii University, 1239 Siping Road, Shanghai 200092, China \\ *(Corresponding author: E-mail: 08_chao_zhang@tongji.edu.cn)
}

Received: 2 June 2009; Revised: 27 July 2009; Accepted: 10 August 2009

\begin{abstract}
Currently, Chinese technical code for fire safety of steel structures in buildings (CECS200) is being revised. This paper intends to give the background of the recommended formulation in CECS200 for temperature calculation of uniformly insulated steel members. Analytical formulations recommended by other codes including EC3, ECCS, SFPE handbook, etc.., and FE method are used for comparison and verification. Theoretical derivation of the exact analytical formulations is also given. Two boundary conditions at the fire-insulation interface have been discussed in the derivation. By investigating the steel temperature of three insulated sections with different section factors which are protected by typical fire protection materials, the formulation recommended by CECS200 is proved to be reasonable and simple for engineering usage.
\end{abstract}

Keywords: Fire resistance, uniformly insulated steel members, 1D model, temperature calculation, analytical formulations, FEM

\section{INTRODUCTION}

Bare Steel is frangible to fire by its high conductivity and low specific heat capacity. As a result, insulation is always required for steel members to ensure the stability of the building in fire condition. Historically, the most common methods of insulation have included concrete encasement, envelopment in gypsum plaster or gypsum board and spray application of light weight cementitous or mineral fiber spray-applied fire resistive materials (SFRMs). In recent years, intumescent coatings have been widely used in fire protection engineering. Unlike the traditional fire protection materials like concrete, gypsum, SFRMs, etc.., the intumescent coatings are reactive materials that they are 'inert' at low temperatures but swell to provide a charred layer of low conductivity materials at temperatures of approximately $200-250^{\circ} \mathrm{C}[1]$.

Traditionally, the thickness of insulation needed on steel members is determined by standard fire tests [2-3]. In standard fire tests, after a specified period of time, if the insulated member withstands the fire exposure without exceeding any of the endpoint failure criteria, the insulation is sufficient and the thickness of the insulation is considered to be the limit value of the protection. The standard fire conditions in the tests are represented in terms of the standard gas temperature history specified in different standards like ASTM E119 [2], ISO834 [3], etc... The widely used endpoint failure criteria in fire resistance test standard is that the maximum mean steel temperature must be lower than the critical temperature which is the temperature that causes structure collapse in a fire situation.

As an alternative to standard fire testing, analytical methods have been developed to evaluate the fire protection materials [4-7]. Analytical methods require solution of 2D (ignoring temperature gradient along the length of the member) transient heat transfer diffusion equation [8], which is usually complicated. In practice, a simplified 1D condensed heat transfer model, as shown in Figure 1, based on lumped capacitance concept has been adopted by different codes [4-7]. This 
concept assumes that the temperature distribution is uniform inside the entire steel section. Using this 1D model, various mathematical techniques including separation of variables [9], Laplace transform [10] and Green's function approach [11] have been developed to give analytical formulations for uniformly insulated steel members in fire. There are two boundary conditions, which are Dirichlet and Neumann boundary conditions, at the fire-insulation interface for the solution of the 1D diffusion equation. In reference [9], Dirichlet boundary condition has been assumed and the derived formulation has been adopted by Eurocode 3[4]. In references [10] and [11], both Dirichlet and Neumann boundary conditions can be considered. Assuming Dirichlet boundary condition, Silva [12] derives a simple formulation of the problem which has been recommended for the revision of the Brazilian Standard 14323 [13].

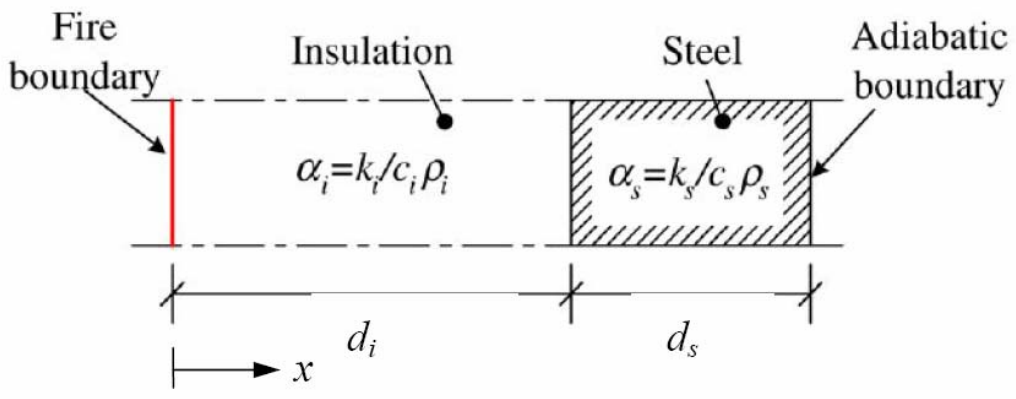

Figure 1. 1D Heat Transfer Model

Currently, Chinese technical code for fire safety of steel structure in buildings (CECS200) [7] is being revised. This paper intends to give the background of the formulation given by CECS200 [7] for temperature calculation of uniformly insulated steel members. The exact analytical derivations of the problem are also presented. Three steel I sections with different section factors insulated by typical nonreactive fire protection materials which are normal weight concrete (NWC), gypsum board and SFRMs are investigated. The mean steel temperature calculated by CECS200 [7], EC3 [4], ECCS [5], SFPE handbook [6] and Silva [12] are compared with the numerical results from the popular FEM program ANSYS [14]. ANSYS is power to solve transient, non-linear heat transfer problems. Its capacity of application in fire condition has been verified by experiments [15]. The same thermal elements used in reference [15] are adopted in this paper. In Appendix, the FEM model is further verified. Detail information about the FEM model is also given in the Appendix.

\section{THEORETICAL BACKGROUND}

\subsection{Governing Equation and Boundary Conditions}

The governing heat transfer equation for the 1D model in Figure 1 is given by

$\alpha_{i} \frac{\partial^{2} T(x, t)}{\partial x^{2}}-\frac{\partial T(x, t)}{\partial t}=0$

where $\alpha_{i}=k_{i} / \rho_{i} c_{i}$ is the thermal diffusivity; $k_{i}$ is the thermal conductivity; and $\rho_{i} c_{i}$ is the thermal capacity, in which $\rho_{i}, c_{i}$ are the density and specific heat of the insulation material, respectively. 
By lumped capacitance concept, the boundary condition at the steel-insulation interface is given by

$$
\begin{aligned}
& -k_{i} \frac{\partial T\left(d_{i}, t\right)}{\partial x}=\frac{c_{s} \rho_{s}}{A_{p} / V} \frac{\partial T\left(d_{i}, t\right)}{\partial t} \\
& T_{s}(t)=T\left(d_{i}, t\right)
\end{aligned}
$$

At the fire-insulation interface, the Neumann boundary condition is

$$
-k_{i} \frac{\partial T(0, t)}{\partial x}=\left(h_{c}+h_{r}\right)\left[T_{g}(t)-T(0, t)\right]
$$

where, $h_{c}=25 \mathrm{~W} /\left(\mathrm{m}^{2} \mathrm{~K}\right)$ is the convective heat transfer coefficient; $h_{r}$ is the radiative heat transfer coefficient, given by

$$
h_{r}=\sigma \varepsilon_{r e s}\left[\left(T_{g}(t)+273\right)^{2}+(T(0, t)+273)^{2}\right] \times\left[T_{g}(t)+273+T(0, t)+273\right]
$$

where, $\sigma=5.67 \times 10^{-8} \mathrm{~W} /\left(\mathrm{m}^{2} \mathrm{~K}^{4}\right)$ is the Stefan-Boltzmann constant; and $\varepsilon_{\text {res }}$ is the resultant emissivity for radiation heat transfer, given by

$$
\varepsilon_{\text {res }}=\frac{1}{1 / \varepsilon_{g}+1 / \varepsilon_{m}-1} \approx \varepsilon_{g} \varepsilon_{m}
$$

where $\varepsilon_{g}$ and $\varepsilon_{m}$ are the emissivity of the fire and insulation surface respectively. The emissivity of a real surface is a function of the surface temperature [8, 16-17], but in present codes [4-7], constant values of emissivity are adopted. In this paper, constant values with $\varepsilon_{g}=1.0$ and $\varepsilon_{g}=0.7$ recommended in EC4 [18] are used.

The Neumann boundary condition at the fire-insulation interface is complex. In practice, Dirichlet boundary condition has been widely adopted in deriving temperature formulations for uniformly insulated steel members $[4,7,9,12]$, which is given by

$$
T(0, t)=T_{g}(t)
$$

Eq. 7 assumes that there is no heat loss through surface convection and radiation, thus the insulation can effectively 'block' the thermal energy at the fire-insulation interface [19]. This assumption gives good prediction of steel temperature for insulation with low density and low conductivity but yields conservative results for insulation with high density and high conductivity [16]. In reference [16], two insulation materials, ceramic fibre blanket and concrete, have been studied, and temperature-dependent emissivity has been used. Using Green's function, Wang et al. [11] shows that for steel sections insulated by gypsum and concrete, the Dirichlet boundary condition will yield higher steel temperature than the real ones using Neumann boundary condition. 


\subsection{Exact Analytical Derivations}

\subsubsection{Separation of Variables}

Introducing a state variable defined by

$\theta(x, t)=T(x, t)-T_{0}$

Then, the governing equation Eq. 1 and the boundary conditions Eqs. 2 and 7 are expressed as

$\alpha_{i} \frac{\partial^{2} \theta(x, t)}{\partial x^{2}}-\frac{\partial \theta(x, t)}{\partial t}=0$

$-k_{i} \frac{\partial \theta\left(d_{i}, t\right)}{\partial x}=\frac{c_{s} \rho_{s}}{A_{p} / V} \frac{\partial \theta\left(d_{i}, t\right)}{\partial t}$

$\theta(0, t)=0$

Solving the correlated Eqs. 9 to 12 with the following initial condition

$\theta(x, 0)=\theta_{0}, t=0$

we get

$\theta(x, t) / \theta_{0}=\sum_{n=1}^{\infty} C_{n} \exp \left(-\frac{\alpha_{i} \xi_{n}^{2}}{d_{i}^{2}} t\right) \sin \left(\xi_{n} \frac{x}{d_{i}}\right)$

From Eq. 3, we get $\theta_{s}(t)=\theta\left(d_{i}, t\right)$, then

$\theta_{s}(t) / \theta_{0}=\sum_{n=1}^{\infty} C_{n} \exp \left(-\frac{\alpha_{i} \xi_{n}^{2}}{d_{i}^{2}} t\right) \sin \left(\xi_{n}\right)$

In which, $\xi_{n}$ is obtained by solving the following transcendental equation

$\xi_{n} \tan \xi_{n}=\mu$

where,

$\mu=\frac{c_{i} \rho_{i}}{c_{s} \rho_{s}} d_{i}\left(A_{p} / V\right)$

The coefficients $C_{n}$ in Eq. 14 are obtained by

$C_{n}=\frac{2\left(\xi_{n}^{2}+\mu^{2}\right)}{\xi_{n}\left(\xi_{n}^{2}+\mu^{2}+\mu\right)}$ 
In the case that $\mu$ is small, Eq. 14 can be approximated as

$\theta_{s}(t) / \theta_{0}=\left\{\begin{array}{cc}0 & t \leq t_{d} \\ \exp \left(-\frac{t-t_{d}}{\tau}\right) & t>t_{d}\end{array}\right.$

where,

$t_{d}=\mu \tau / 8, \quad \tau=\frac{c_{s} \rho_{s} d_{i}}{\left(A_{p} / V\right) k_{i}}\left(1+\frac{\mu}{3}\right)$

Assuming the thermal properties are constant, temperature response can be calculated for the insulated steel member subject to a time-varying boundary condition, using the principle of superposition (Duhamel's theorem), as

$T_{s}(t)=\int_{0}^{t} T(t-\zeta) d\left(1-\theta_{s}(\zeta) / \theta_{0}\right)$

where $T$ is the time-varying heating curve. The ISO834 standard fire curve can be approximated by a sum of exponential terms as

$T=\sum_{j=0}^{3} B_{j} \exp \left(-\beta_{j} t\right)$

where $B_{j}$ and $\beta_{j}$ are as given in Table 1 .

Table $1 . B_{j}, \beta_{j}$ for ISO834 Standard Curve

\begin{tabular}{ccccc}
\hline$j$ & 0 & 1 & 2 & 3 \\
\hline$B\left({ }^{\circ} \mathrm{C}\right)$ & 1325 & -430 & -270 & -625 \\
$\beta\left(\mathrm{h}^{-1}\right)$ & 0 & 0.2 & 1.7 & 19 \\
\hline
\end{tabular}

Substituting Eqs. 14 and 21 into Eq. 20 we get the steel temperature

$T_{s}=\sum_{n=1}^{\infty} \sum_{j=0}^{3} \frac{B_{j} C_{n} \sin \left(\xi_{n}\right)}{1-\beta_{j} d_{i}^{2} /\left(\alpha_{i} \xi_{n}^{2}\right)} \times\left[\exp \left(-\beta_{j} t\right)-\exp \left(-\frac{\alpha_{i} \xi_{n}^{2}}{d_{i}^{2}} t\right)\right]$

Substituting Eqs. 18 and 21 into Eq. 20, we get the approximate steel temperature, for $t>t_{d}$,

$$
T_{s}=\sum_{j=0}^{3} \frac{B_{j}}{1-\beta_{j} \tau} \times\left[\exp \left(-\beta_{j}\left(t-t_{d}\right)-\exp \left(-\frac{t-t_{d}}{\tau}\right)\right]\right.
$$

To consider time-varying material properties, an approximate temperature time derivative is derived by Wickström[9] from Eq. 23 as

$\frac{d T_{s}}{d t}=\frac{T-T_{s}}{\tau}-\left(e^{\mu / 10}-1\right) \frac{d T}{d t}$ 
Eq. 24 is adopted by EC3 [4], and the increment of steel temperature $\Delta T_{s}$ within a time interval $\Delta t$ is given by

$\Delta T_{s}=\frac{k_{i} A_{p} / V}{c_{s} \rho_{s} d_{i}} \frac{T_{g}-T_{s}}{(1+\mu / 3)} \Delta t-\left(e^{\mu / 10}-1\right) \Delta T_{g} \quad\left(\Delta \mathrm{T}_{\mathrm{s}} \geq 0\right.$, if $\left.\Delta \mathrm{T}_{\mathrm{g}}>0\right)$

where, $\Delta t \leq 30$ s for insulated steel members.

\subsubsection{Laplace Transform}

An alternative solution of the problem using Laplace transfer is given by ECCS [5] as

$\frac{d T_{s}}{d t}=A^{\prime}\left(T_{g}-T_{s}\right)-B^{\prime} \frac{d T_{g}}{d t}$

where

$$
\begin{aligned}
& A^{\prime}=\frac{1}{\left(\frac{c_{s} \rho_{s}}{A_{p} / V}\right)\left(\frac{d_{i}}{k_{i}}+\frac{1}{h_{c}+h_{r}}\right)\left(1+\frac{\mu}{N}\right)} \\
& B^{\prime}=b /(1+N / \mu)
\end{aligned}
$$

with $N$ and $b$ as weighting factors. Certainly, for limiting case $\left(h_{c}+h_{r}\right) \rightarrow \infty$ Neumann boundary is equivalent to Dirichlet boundary. At this case,

$$
\begin{aligned}
& b=\frac{1+\mu / 4}{2(1+5 \mu / 8)} \\
& N=2(b+1)
\end{aligned}
$$

\subsection{Simple Derivation in CECS200}

In Chinese Code CECS200 [7], the following assumptions are made in deriving the formulation for temperature calculation of insulated steel members,

(1) Dirichlet boundary is safely assumed at fire-insulation interface;

(2) The temperature distribution within the insulation is linear; and

(3) The temperature distribution within the steel is uniform.

At time increment $\Delta t$, the total energy transferred to the steel is

$$
\Delta Q=\frac{k_{i}}{d_{i}}\left[T(t)-T_{s}(t)\right] A_{p} \Delta t
$$

The energy absorbed by the steel is

$$
\Delta Q_{s}=c_{s} \rho_{s} V\left[T_{s}(t+\Delta t)-T_{s}(t)\right]
$$


The energy absorbed by the insulation is

$\Delta Q_{i}=\frac{T_{s}(t+\Delta t)-T_{s}(t)+\Delta T_{g}}{2} c_{i} \rho_{i} A_{p} d_{i}$

By energy balance, we have

$\Delta Q=\Delta Q_{s}+\Delta Q_{i}$

Substituting Eqs. 31, 32 and 33 into Eq. 34 and ignoring the secondary term, we get the formulation given by CECS200 [7] as

$\Delta T_{s}=\frac{k_{i} A_{p} / V}{c_{s} \rho_{s} d_{i}} \frac{T_{g}-T_{s}}{(1+\mu / 2)} \Delta t$

\section{COMPARISON OF DIFFERENT FORMULATIONS}

\subsection{Different Formulations}

Eq. 25, Eq. 26 and Eq. 35 give the formulations recommended by EC3 [4], ECCS [5] and CECS200 [7] respectively. In SFPE handbook [6] different formulations are recommended based on the value of $\mu$. For $\mu>1 / 2$, the same formulation in CECS200 or Eq. 35 is recommended; and for $\mu \leq 1 / 2$,

$\Delta T_{s}=\frac{k_{i} A_{p} / V}{c_{s} \rho_{s} d_{i}}\left(T_{g}-T_{s}\right) \Delta t$

The formulation recommended by Silva [13] is

$\Delta T_{s}=\frac{k_{i} A_{p} / V}{c_{s} \rho_{s} d_{i}} \frac{T_{g}-T_{s}}{(1+\mu / 4)} \Delta t-\frac{\Delta T_{g}}{4 / \mu+1}$

The formulation recommend by Pettersson et al. [20] is

$\Delta T_{s}=\frac{A_{p} / V}{c_{s} \rho_{s}} \frac{1}{\left(\frac{d_{i}}{k_{i}}+\frac{1}{h_{c}+h_{r}}\right)} \frac{T_{g}-T_{s}}{\left(1+\frac{\mu}{2}\right)} \Delta t-\frac{\Delta T_{g}}{\frac{2}{\mu}+1}$

\subsection{Material and Geometric Properties}

Figure 2 shows the schematics of the analyzed section. Totally 3 typical steel I section with different section factors are investigated. The geometric properties of the sections are given in Table 2. The thickness of all sections is $50 \mathrm{~mm}$.

Table 3 gives the thermal properties of fire protection materials [21] which are NWC, gypsum board and SFRMs. Temperature-independent properties are investigated. The thermal properties of the steel are $\rho_{s}=7850 \mathrm{~kg} / \mathrm{m}^{3}$ and $c_{s}=600 \mathrm{~J} /\left(\mathrm{kg}^{\circ} \mathrm{C}\right)$. 


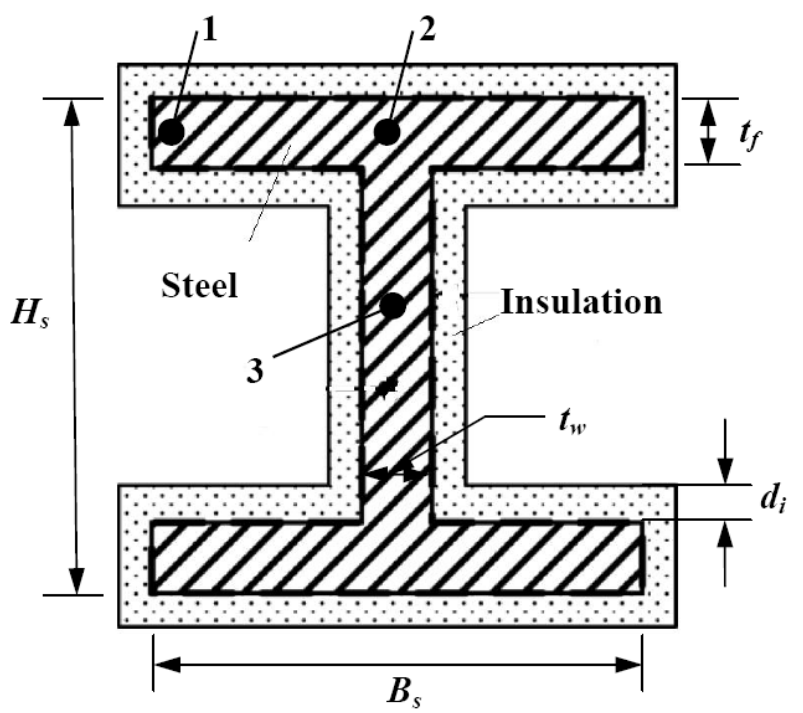

Figure 2. Schematics of Analyzed Section

Table 2. Geometric Properties of Analyzed Sections

\begin{tabular}{ccccccc}
\hline $\begin{array}{c}\text { Section } \\
\text { name }\end{array}$ & $\begin{array}{c}B_{s} \\
(\mathrm{~mm})\end{array}$ & $\begin{array}{c}H_{s} \\
(\mathrm{~mm})\end{array}$ & $\begin{array}{c}t_{w} \\
(\mathrm{~mm})\end{array}$ & $\begin{array}{c}t_{f} \\
(\mathrm{~mm})\end{array}$ & $\begin{array}{c}A_{p} / V \\
\left(\mathrm{~m}^{-1}\right)\end{array}$ & $\begin{array}{c}d_{\mathrm{i}} \\
(\mathrm{mm})\end{array}$ \\
\hline$\# 1$ & 200 & 200 & 8 & 12 & 190.72 & 50 \\
$\# 2$ & 300 & 300 & 10 & 15 & 152.14 & 50 \\
$\# 3$ & 400 & 400 & 15 & 25 & 93.86 & 50 \\
\hline
\end{tabular}

Table 3. Thermal Properties of Insulation Materials

\begin{tabular}{lccc}
\hline & $\begin{array}{c}\rho_{i} \\
\left(\mathrm{~kg} / \mathrm{m}^{3}\right)\end{array}$ & $\begin{array}{c}c_{i} \\
\mathrm{~J} /\left(\mathrm{kg}^{\circ} \mathrm{C}\right)\end{array}$ & $\begin{array}{c}k_{i} \\
\mathrm{~W} /\left(\mathrm{m}^{\circ} \mathrm{C}\right)\end{array}$ \\
\hline SFRM & 250 & 800 & 0.12 \\
gypsum board & 800 & 1700 & 0.2 \\
NWC & 2300 & 1200 & 1.6 \\
\hline
\end{tabular}

\subsection{Results and Discussions}

Figure 3 to Figure 5 show the steel temperature-time curves of insulated sections resulting from different methods. The steel temperatures obtained with FEM are taken as the average value of the temperatures measured at the location of points 1,2 and 3, as shown in Figure. 2.

When calculating by Eqs. 25, 26, 37 and 38, the increments of the steel temperature are negative at early heating process, which is illegal to physics law. To avoid this, in practice we assume the steel temperature increments as zero if the values calculated by those equations are negative. 
When calculating by Eqs. 26 and 38, the values of $h_{r}$ are required. From Eq. 5 we know in order to get $h_{r}$, the value of the surface temperature of the insulation, $T(0, \mathrm{t})$ should be known beforehand. However, $T(0, t)$ is an unknowable variable. In practice when calculating $h_{r}$ we safely take fire temperature as the surface temperature that $T(0, \mathrm{t}) \approx T_{\mathrm{g}}(\mathrm{t})$. This treatment has been used by Wong and Ghojel [16] in their analysis.

As shown in Figure 3, when insulated by SFRMs, for all sections steel temperature - time curves given by EC3 [4], ECCS [5], CECS200 [7] and Silva [12] fit very well. Curves given by SFPE handbook [6] and Pettersson et al. [20] deviate from curves given by other four formulations. Comparatively, SFPE handbook [6] over-predicts the steel temperature and Pettersson et al. [20] under-predicts the steel temperature.

As shown in Figure 4, when insulated by gypsum board, for all sections temperature - time curves given by EC3 [4], ECCS [5] and Silva [12] fit well. CECS200 [7] and SFPE handbook [6] give the same results which fit well with the results given by EC3, ECCS and Silva at late heating stage but safely deviate from those results at early and mid heating stage. Comparing with other formulations, Perttersson et al. [20] under-predicts the steel temperature during the whole heating period.

As shown in Figure 5, when insulated by NWC, for all sections temperature - time curves given by EC3 [4], ECCS [5] and CECS200 [7] and SFPE handbook [6] fit very well. Silva [12] gives similar but slightly conservative results. Perttersson et al. [20] gives unsafe results.

As shown in Figures. 3-5, comparing with the 'exact' FEM results, except Pettersson et al. [20] under-predicts the steel temperature all other analytical methods will over-predict the steel temperature. Results also show section factors have little effect on the relationship between different curves.

\section{CONCLUSIONS}

Based on the results of this study, the following conclusions can be drawn:

- Comparing with the 'exact' FEM method, except formulation recommended by Pettersson et al. [20] other formulations will yield conservative results. This is because in the derivation of those formulations, Dirichlet boundary has been assumed at the fire-insulation interface.

- Formulations recommended by EC3 [4] and ECCS [5] nearly give the same results. Results given by formulations recommended by CECS200 [7] fit well with the results given by formulations recommended by EC3 [4], ECCS [5] and Silva [12].

- When calculating by formulation recommended by CECS200 [7], there will not occur unreasonable situation that steel temperature increment is negative in early heating state. Considering its simple form, formulation recommended by CECS200 [7] is preferable for engineering usage. 


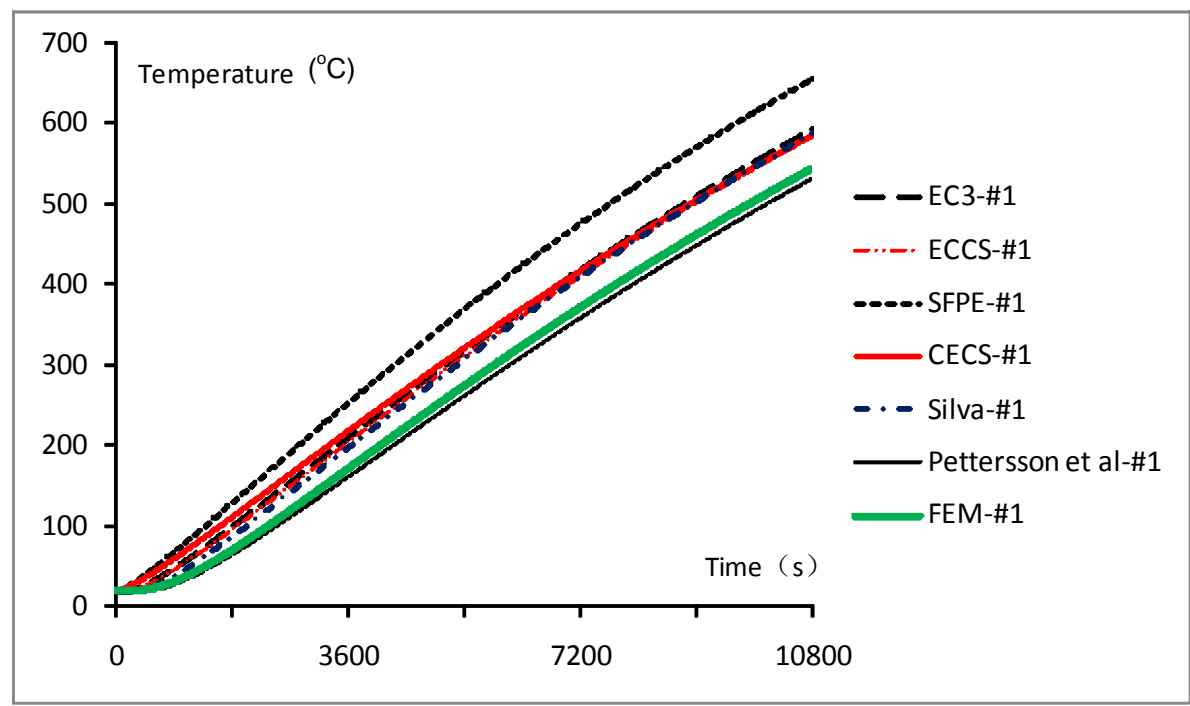

(a) $1 \#$ section

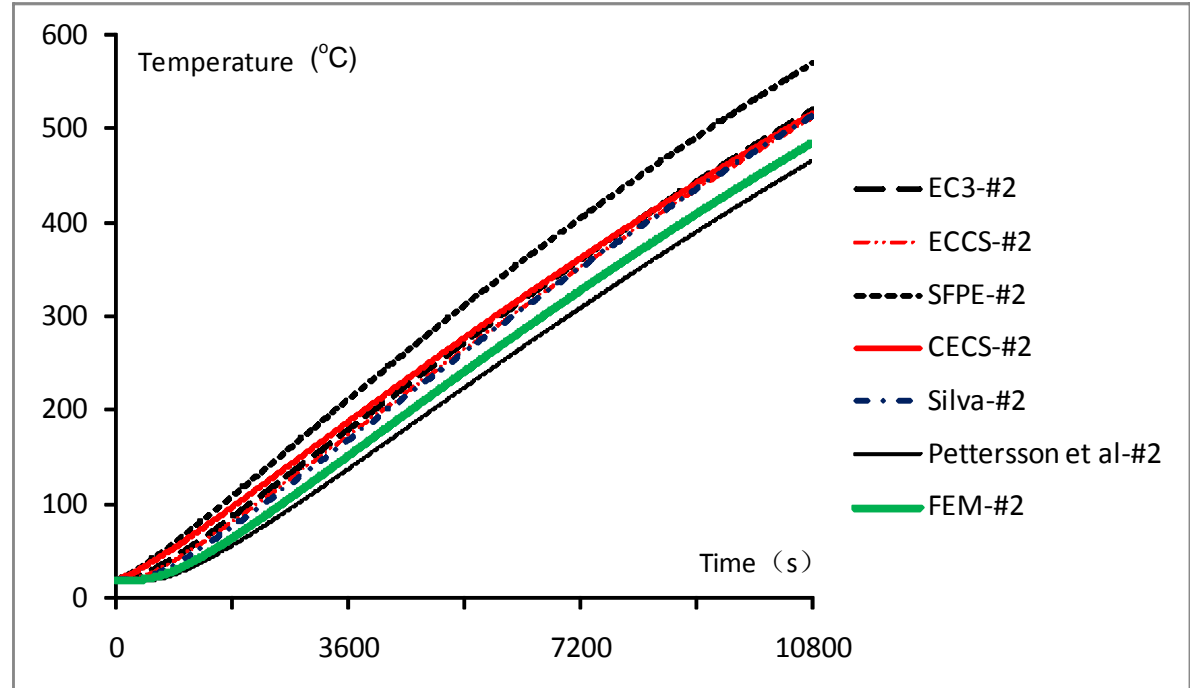

(b) $2 \#$ section

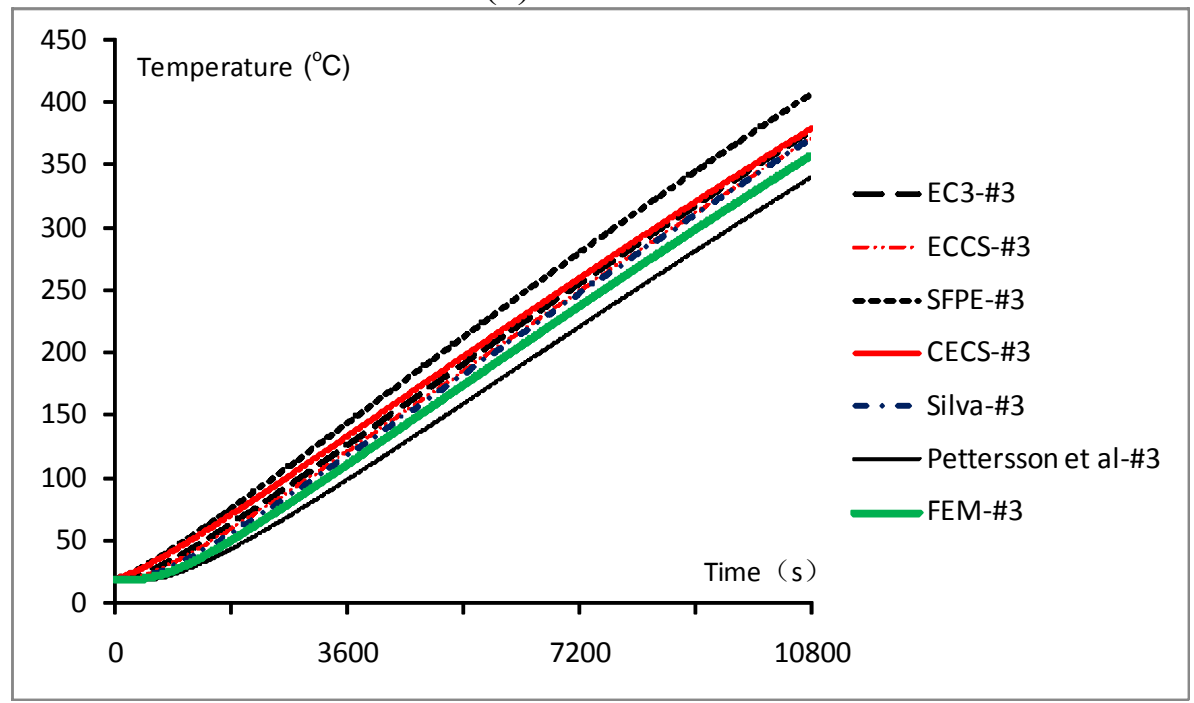

(c) $3 \#$ section

Figure 3. Results of Steel Temperature when Insulated by SFRMs 


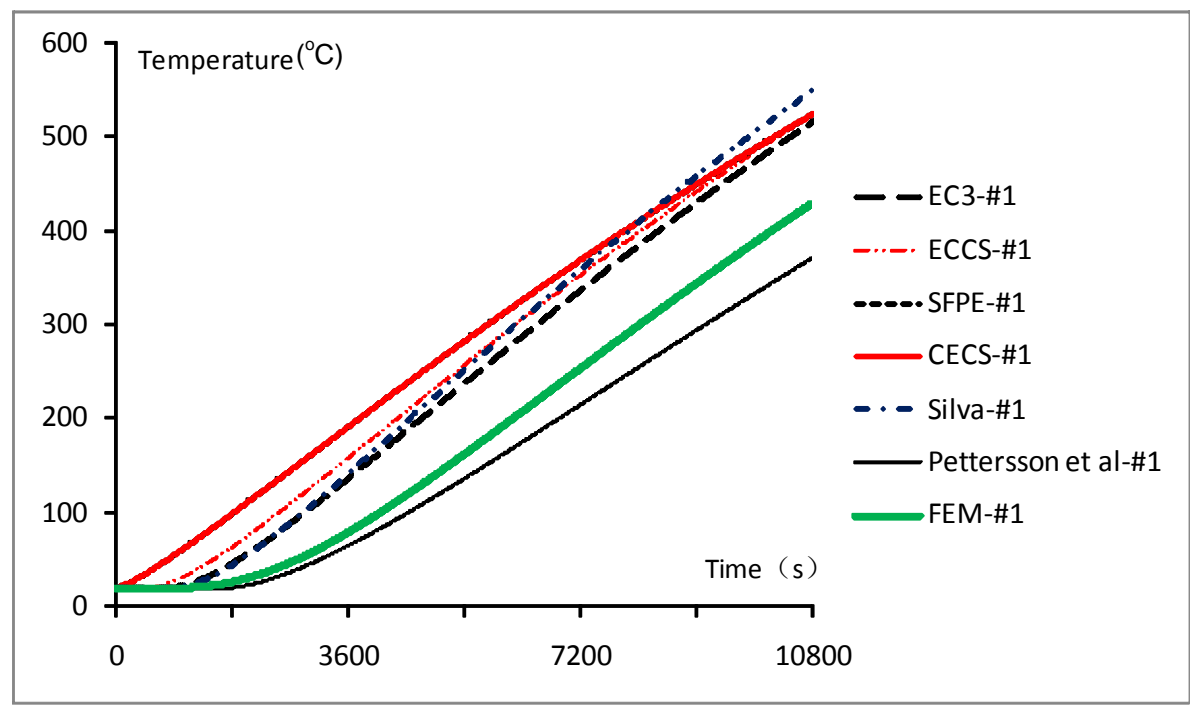

(a) $1 \#$ section

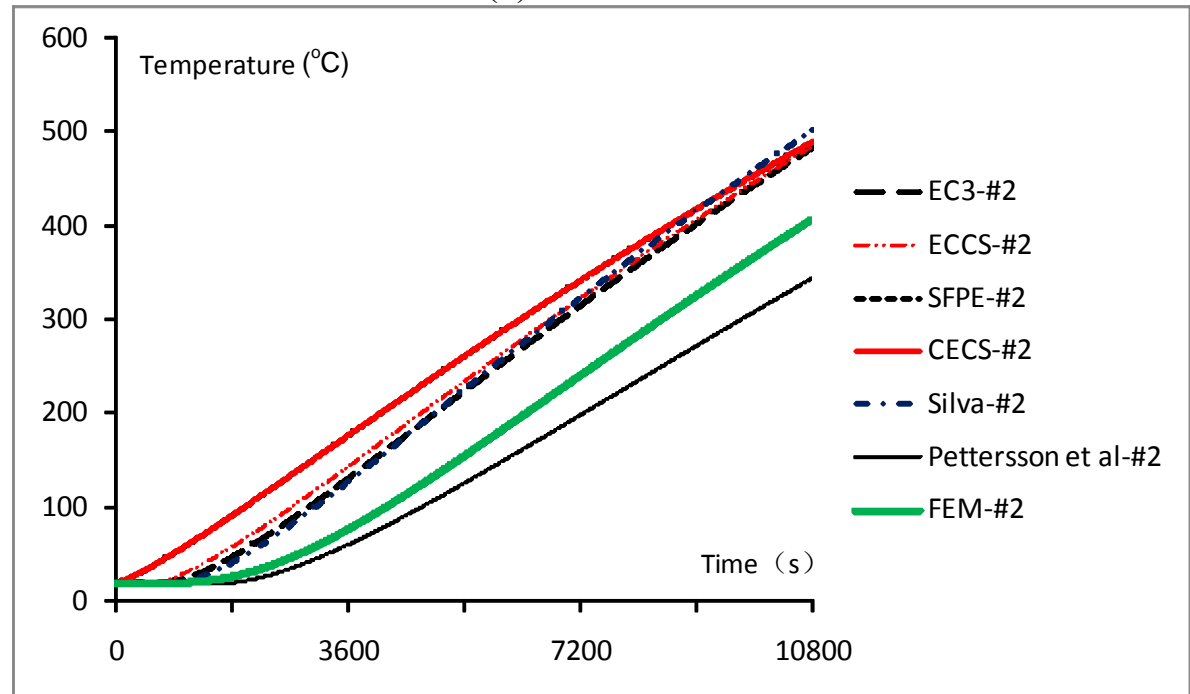

(b) $2 \#$ section

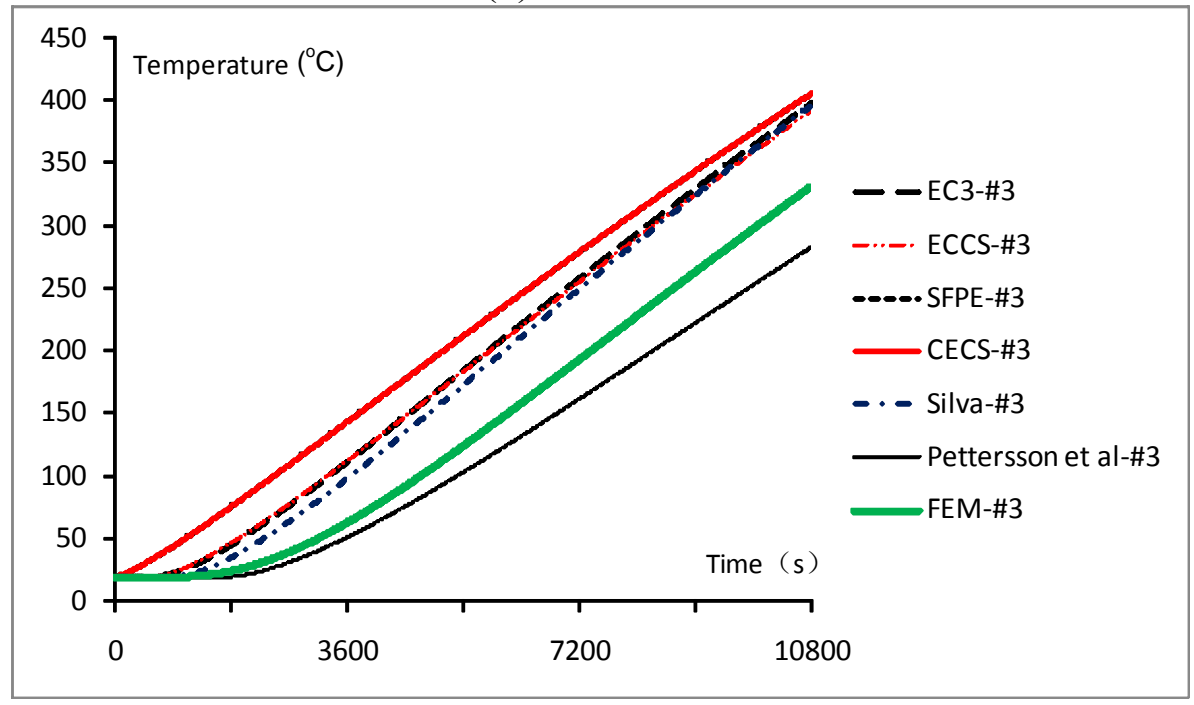

(c) $3 \#$ section

Figure 4. Results of Steel Temperature when Insulated by Gypsum Board 


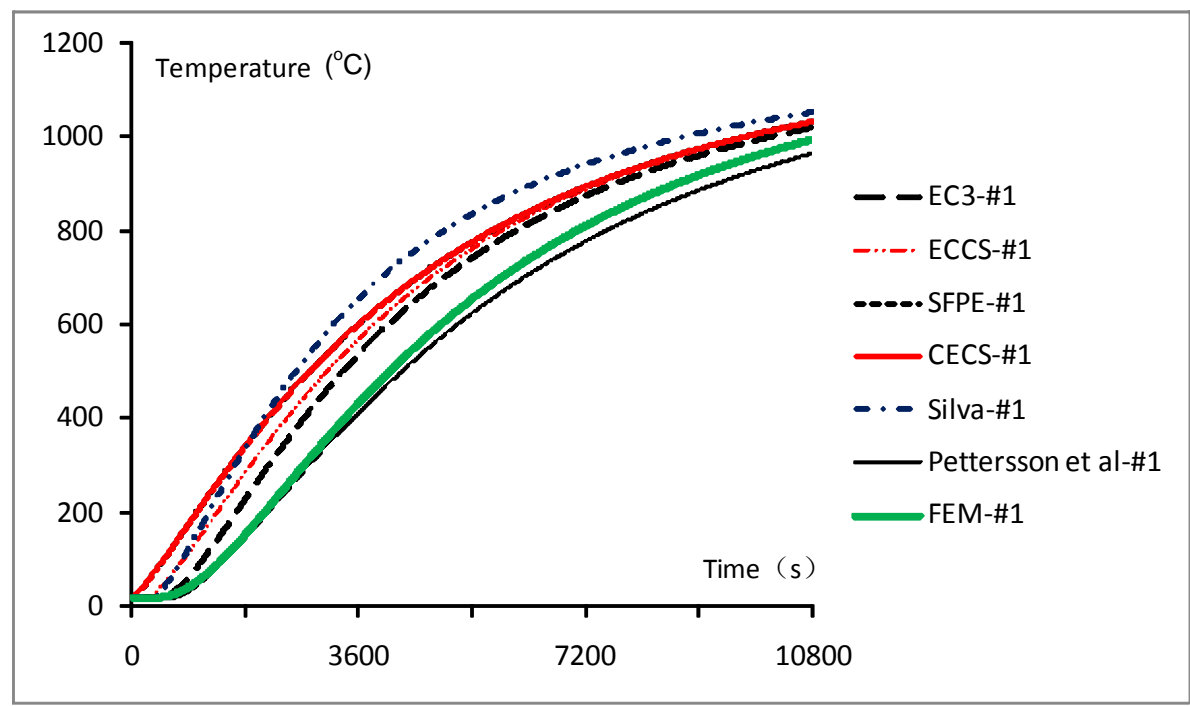

(a) $1 \#$ section

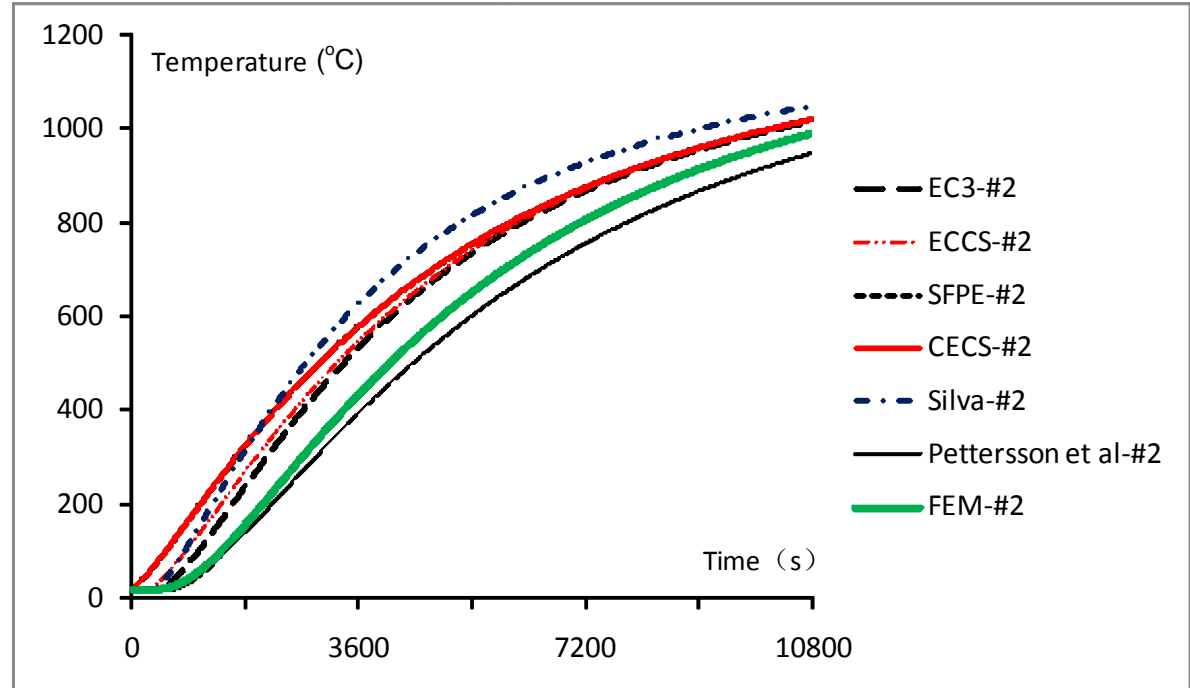

(b) $2 \#$ section

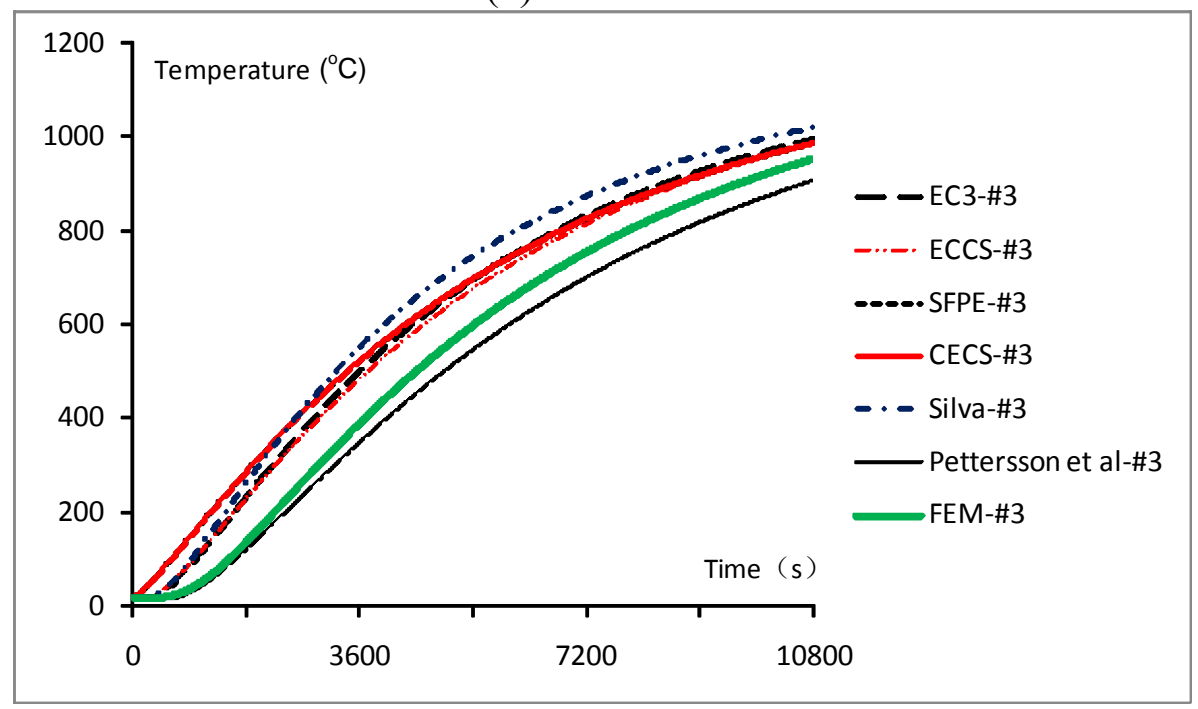

(c) $3 \#$ section

Figure 5. Results of Steel Temperature when Insulated by NWC 


\section{APPENDIX}

In numerical simulation by ANSYS, 2D thermal solid element PLANE55 and thermal surface effect element SURF151 are adopted.

PLANE55 can be used as a plane element or as an axisymmetric ring element with a two-dimensional thermal conduction capacity. The element has four nodes with a single degree of freedom, temperature, at each node. The element is applicable to a two-dimensional, steady-state or transient thermal analysis. It can also compensate for mass transport heat flow from a constant velocity field.

SURF151 may be used for various load and surface effect applications. It may be overlaid onto a face of any $2 \mathrm{D}$ thermal solid element (except axisymmetric harmonic elements). The element is applicable to two-dimensional thermal analysis. Various loads and surface effects may exist simultaneously. For example, SURF151 can be overlaid onto the surface of PLANE55 to simulate the effect of thermal radiation from ambient air to steel section.

Problem: A ceramic wall is initially uniform in temperature at $20{ }^{\circ} \mathrm{C}$ and has a thickness of $30 \mathrm{~mm}$. It is suddenly exposed to a radiation source on the right side at $1000^{\circ} \mathrm{C}$. The left side is exposed to room air at $20{ }^{\circ} \mathrm{C}$ with a radiation surrounding temperature of $20{ }^{\circ} \mathrm{C}$. Properties of the ceramic are $k$ $=3.0 \mathrm{~W} /\left(\mathrm{m}^{\circ} \mathrm{C}\right), \rho=1600 \mathrm{~kg} / \mathrm{m}^{3}$, and $c=800 \mathrm{~J} /\left(\mathrm{kg}{ }^{\circ} \mathrm{C}\right)$. Radiation heat transfer with the surroundings at $T_{r}$ (in ${ }^{\circ} \mathrm{C}$ ) may be calculated from

$q_{r}=0.8 \sigma A\left[(T+273)^{2}-\left(T_{r}+273\right)^{2}\right]$

The convection heat transfer coefficient from the left side of the plate is given by

$h=1.92 \Delta T^{1 / 4}$

Determine the temperature distribution in the plate after $15,30,45,60,90,120$, and $150 \mathrm{~s}$.

Holman[8] solves the above problem by finite difference method (FDM). Here we solve the same problem by FEM using ANSYS. Figure. 6 shows the results from FDM and FEM. It finds the results from FEM fit well with the results given by Holman using FDM, which verify the validation of the FEM in this paper.

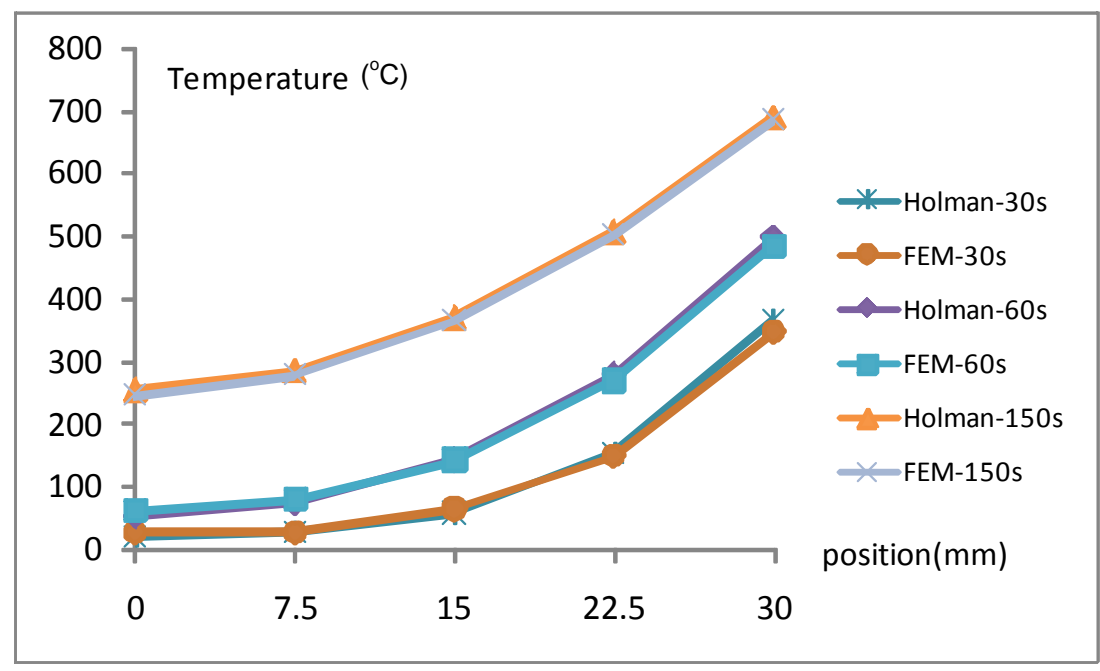

Figure 6. Comparison of Results by FEM and Holman [8] 


\section{ACKNOWLEGEMENT}

The work reported hereinabove is financially supported by the National Natural Science Foundation of China by the contracts 50738005, 50621062. The support is gratefully acknowledged.

\section{REFERENCES}

[1] Fire Resistance of Steel-framed Buildings 2006 Edition, Corus Construction \& Industrial, 2006.

[2] Standard Test Methods for Fire Tests of Building Construction and Materials, ASTM E119-00a, ASTM International, West Conshohocken, PA, 2000.

[3] BS 476-20, British Standard BS 476, Part 20: Method for Determination of the Fire Resistance of Load Bearing Elements of Construction (General Principles), British Standard Institution. London, 1987.

[4] EN 1993-1-2, Eurocode 3: Design of Steel Structures - Part 1-2: General Rules - Structural Fire Design, British Standard Institution, London, 2005.

[5] ECCS Technical Committee 3, European Recommendations for the Fire Safety of Steel Structures. Amsterdam: Elsevier Scientific Publishing Company, 1983.

[6] Milke, J.A., Analytical Methods for Determining Fire Resistance of Steel Members, The SFPE Handbook of Fire Protection Engineering, $3^{\text {rd }}$ ed. National Fire Protection Association, MA, 2002.

[7] China Association for Engineering Construction Standardization (CECS200), Technical Code for Fire Safety of Steel Structure in Buildings (in Chinese), Beijing, China Planning Press, 2006.

[8] Holman, J.P., Heat Transfer, $9^{\text {th }}$ ed. McGraw-Hill Inc., 2002.

[9] Wickstrőm, U., "Temperature Analysis of Heavily-insulated Steel Structures Exposed to Fire," Fire Safety Journal. 1985, Vol. 9, No. 3, pp. 281-5.

[10] Melinek, S.J., Thomas, P.H., "Heat Flow to Insulated Steel," Fire Safety Journal, 1987, Vol. 12 , pp. $1-8$.

[11] Wang, Z.H., Au, S.K., Tan, K.H., "Heat Transfer Analysis Using a Green's Function Approach for Uniformly Insulated Steel Members Subjected to Fire", Engineering Structures, 2005, Vol. 27, pp. 1551-62.

[12] Valdir Pignatta e Silva, "Determination of the Steel Fire Protection Material Thickness by An Analytical Process - A Simple Derivation”, Engineering Structures, 2005, Vol. 27, pp. 2036-43.

[13] Valdir Pignatta e Silva and Ricardo Hallal Fakury, "Brazilian Standard for Steel Structures Fire Design”, Fire Safety Journal, 2002, Vol. 37, No. 2, pp. 217-27.

[14] ANSYS, User's Manual.

[15] Ding, J., Li, G.Q. and Sakumoto, Y., "Parametric Studies on Fire Resistance of Fire-resistant Steel Members", Journal of Constructional Steel Research, 2004, Vol. 60, pp. 1007-27.

[16] Wong, M.B. and Ghojel, J.I., "Sensitivity Analysis of Heat Transfer Formulations for Insulated Structural Steel Components”, Fire Safety Journal, 2003, Vol. 38, pp. 187-201.

[17] Staggs, J.E.J. and Phylaktou, H.N., "The Effects of Emissivity on the Performance of Steel in Furnace Tests," Fire Safety Journal, 2008, Vol. 43, pp. 1-10.

[18] EN 1994-1-2, Eurocode 4: Design of Composite Steel and Concrete Structures - Part 1-2: General Rules - Structural Fire Design, British Standard Institution, London, 2005. 
[19] Wang, Z.H. and Tan, K.H., "Sensitivity Study of Time Delay Coefficient of Heat Transfer Formulations for Insulated Steel Members Exposed to Fire", Fire Safety Journal, 2006, Vol. 41, pp. 31-8.

[20] Pettersson, O., Magnussen, S. and Thor, J., "Fire Engineering Design of Steel Structures," Stockholm: Swedish Institute of Steel Construction, 1976.

[21] Li, G.Q., Han, L.H., Lou, G.B. and Jiang, S.C., "Fire Resistance Design of Steel and Steel-concrete Structures (in Chinese)", China Architecture \& Building Press, Beijing, China, 2006. 